Revista Aportes para la Integración Latinoamericana Año XXIV, N 38/Diciembre 2018, ISSN 2468-9912. DNDA: 5355295 en línea

Noemí Mellado

De lo Global a lo Regional en un marco de incertidumbres

\title{
DE LO GLOBAL A LO REGIONAL EN UN MARCO DE INCERTIDUMBRES
}

En un marco de incertidumbre de las relaciones económicas internacionales a raíz de las transformaciones socioeconómicas, financieras y políticas a nivel global y su influencia en América Latina como región; los procesos de integración se reconfiguran en virtud de los factores externos de influencia.

En este escenario cambiante Latinoamérica se convierte en una de las más desiguales del mundo. Tres factores -moneda, salud y formación de cadenas de valor- permiten delinear una caracterización emergente de las realidades y desafíos actuales por los que atraviesa la región.

En el desarrollo del Tema Central de este nuevo número de nuestra revista, "Enfoques Teóricos-metodológicos sobre Unificación Monetaria en MERCOSUR. Reapertura del Debate", abordado por Alberto José Hurtado Briceño, Sadcidi Zerpa de Hurtado y José Ustorgio Mora Mora se analizan las discusiones actuales sobre la Integración Monetaria en el MERCOSUR. Los autores señalan que ya desde 1987 se plantea la necesidad de avanzar en los acuerdos regionales que permitan lograr la unificación monetaria. Desde entonces se han sugerido distintos enfoques teóricos-metodológicos acerca de cómo lograrlo. El presente artículo tiene como propósito presentar las contribuciones teóricas-metodológicas realizadas acerca del tema y contribuir a reabrir el debate sobre las alternativas a seguir para la construcción de la moneda única en el mercado común suramericano. Para ello se identifican el origen y los enfoques teóricosmetodológicos planteados a la integración monetaria del MERCOSUR.

En la sección Estudios se presenta el trabajo de Milena Olivares Homez, "El Consejo de Salud Suramericano y la creación de un régimen regional de salud" en el que se abordan los principales postulados de los regímenes internacionales desde la teoría neoliberal y se los aplica al caso del Consejo de Salud Sudamericano (CSS), de la UNASUR, analizando si los desarrollos de este último pueden considerarse como un régimen regional de salud. Se revisa detalladamente el proceso de institucionalización del consejo y de sus organismos subsidiarios con una metodología cualitativa, cuyas fuentes primarias son textos, acuerdos fundacionales y las entrevistas a personas relacionadas con el tema.

Como trabajo de Opinión se publica "Discusiones sobre autonomía en la recepción de los aportes dependentistas al campo de las Relaciones Internacionales y contribuciones recientes desde el enfoque de Cadenas Globales de Valor" de Mariano Treacy, quien se propone identificar las características de la recepción de los aportes de esta teoría bajo la hipótesis de que esta ha estado mediada por los desarrollos de la Escuela de la Autonomía Latinoamericana y no por los aportes de quienes son considerados los autores dependentistas canónicos en el campo de la Economía Política. Lo que se observa es que el concepto de autonomía que se trabaja desde la escuela latinoamericana es considerablemente diferente del que se trabaja desde la Economía Política. El autor produce un balance crítico y realiza una propuesta para incorporar al marco del análisis a la actual problemática que generan las nuevas cadenas globales de valor. 